\title{
Caracterização tecnológica de novos depósitos de argilas da região sul do Amapá visando aplicações na indústria Cerâmica
}

\section{Technological characterization of new clay deposits in the south region of Amapá aiming applications in the ceramic industry}

Adriano Lima da Silva ${ }^{1}$, Carlos Bruno Barreto Luna ${ }^{1}$, Alexsandra Cristina Chaves ${ }^{1}$, Gelmires de Araújo Neves ${ }^{1}$

\footnotetext{
${ }^{1}$ Unidade Acadêmica de Engenharia de Materiais, UAEMa/CCT/UFCG, Av. Aprígio Veloso, no 882, CEP: 58430-380 Campina Grande-PB. e-mail: adrianolimadasilva@hotmail.com; brunobarretodemaufcg@hotmail.com
}

\begin{abstract}
RESUMO
O presente trabalho teve como objetivo caracterizar dois novos depósitos de argilas (A e B) provenientes da região sul do estado do Amapá, visando estabelecer seus usos adequados como matérias-primas cerâmicas e promover o potencial da indústria cerâmica da região. Foram confeccionados corpos de prova por prensagem uniaxial, sendo aplicada uma prensagem em duas etapas de 13,4 MPa e $20 \mathrm{MPa}$, respectivamente. As amostras foram secas em uma estufa a $110^{\circ} \mathrm{C}$, e submetidas à queima em 850,1000 e $1200^{\circ} \mathrm{C}$. Foram determinadas retração linear de queima, absorção de água, porosidade aparente e módulo de ruptura à flexão, bem como a evolução mineralógica após queima. Finalizando, avaliou-se a microestrutura das argilas sinterizadas a $1200^{\circ} \mathrm{C}$ em um microscópio eletrônico de varredura. Os resultados evidenciaram que a argila A apresentou o melhor desempenho mecânico, tendo uma coloração vermelha e, portanto, tendo potencial para a indústria de cerâmica vermelha. Por outro lado, a argila B apresentou cor clara, devido ao baixo teor de óxido de ferro e, sendo assim, tendo potencial como matéria-prima refratária. No geral, uma argila é adequada para uso em cerâmica branca e outra para cerâmica vermelha.
\end{abstract}

Palavras-chave: Depósitos de argilas, caracterização, propriedades tecnológicas, novos depósitos, aplicação em cerâmica.

\begin{abstract}
The objective of the present work was to characterize two new Clay deposits (A and B) from the south region of Amapá state, aiming to establish their adequate uses as ceramic raw materials and to promote the potential of the ceramic industry in the region. Were prepared specimens by uniaxial pressing, being applied a two phase pressing of $13,4 \mathrm{MPa}$ and $20 \mathrm{MPa}$, respectively. The samples were dried in an oven at $110^{\circ} \mathrm{C}$, and submitted to burning at 850,1000 and $1200^{\circ} \mathrm{C}$. Were determined linear firing shrinkage, water absorption, apparent porosity and modulus of flexural modulus of rupture, as well as mineralogical evolution after burning. Finishing, the microstructure of the sintered clay at $1200^{\circ} \mathrm{C}$ was evaluated in a scanning electron microscope. The results showed that the clay A presented a better mechanical development, having a red coloration and, therefore, potential to the red ceramic industry. On the other hand, the clay B presented a light color, due to a low content of iron oxide and, therefore, having potential as refractory raw material. In general, one clay is suitable to be used in white ceramic and the other in red ceramic.
\end{abstract}

Keywords: Deposits of clay, characterization, technological properties, new deposits, ceramic application.

\section{INTRODUÇÃO}

Material cerâmico, entre dezenas de possíveis definições, pode ser descrito como qualquer produto, composto por matérias-primas inorgânicas constituídas de elementos metálicos e não metálicas, sejam essas naturais ou sintéticas, que em estado de pó, é transformado, por meio de queima, num objeto sólido com aplicações úteis. 
É notório, que os produtos cerâmicos apresentam uma faixa larga de aplicações, desde produtos simples para construção civil até os mais complexos para aplicações como biomateriais, reatores nucleares e na indústria eletrônica [1-3]. Porém, o Brasil se destaca na produção de materiais cerâmicos destinados à construção civil.

A indústria cerâmica brasileira tem grande importância para o país, tanto na geração de divisas como na geração de empregos, sendo o maior destaque as fábricas de cerâmica estrutural. Estima-se uma participação de aproximadamente 300 mil empregos diretos, 1 milhão de empregos indiretos e um faturamento anual em torno de R $\$ 18$ bilhões [4-6]. O setor cerâmico é um grande consumidor de matérias-primas, sendo a principal a argila [7]. Segundo SANTOS [8] a argila é um material natural, terroso, de granulação fina, que geralmente adquire quando umedecido com água certa plasticidade, quimicamente são formadas essencialmente por silicatos hidratados de alumínio, ferro e magnésio.

Geralmente, para uma argila ser considerada adequada à fabricação de produtos estruturais deve, de modo geral, ser de fácil desagregação, apresentar distribuição granulométrica conveniente, adequada combinação entre materiais plásticos e não plásticos, bem como conferir a peça resistência mecânica a verde suficiente para o seu manuseio e resistência após queima. Entretanto, as argilas para cerâmica estrutural são materiais muito heterogêneos, com suas características dependendo da sua formação geológica e localização de extração [9]. Sendo assim, é conveniente realizar caracterizações tecnológicas em argilas, uma vez que se pode adequar à qualidade do produto. Por se tratar de um tema de grande importância, tanto do ponto de vista industrial, quanto do controle da qualidade, alguns trabalhos já foram relatados na bibliografia.

DUTRA et al. [10] estudaram argilas de diferentes regiões do estado do Rio Grande do Norte, visando uma caracterização completa e indicar potencialidades industriais. As argilas passaram por caracterizações de difração de raios $\mathrm{X}$, fluorescência de raios $\mathrm{X}$, distribuição granulométrica, plasticidade e análise térmica diferencial. Os resultados evidenciaram a predominância do mineral argiloso ilita, de composição química homogênea, com duas distribuições de tamanho de partículas e com plasticidades muito diferentes. $\mathrm{O}$ exame das variáveis de processamento e das características intrínsecas de cada material indica o uso destas argilas para fabricação de blocos e telhas, bem como para fabricação de pavimentos e revestimentos.

SILVA et al. [11] investigaram novas ocorrências de argila bentonítica na Paraíba, principalmente no município de Pedra Lavrada, para uso em fluidos de perfuração à base de água. As argilas passaram por caracterizações de análise de tamanho de partícula, termogravimétrica e térmica diferencial, fluorescência de raios-X, difração de raios $\mathrm{X}$, capacidade de troca de cátions e área de superfície específica. As argilas bentonitas foram tratadas com carbonato de sódio em concentrações de 75, 100, 125, 150 e $175 \mathrm{mEq} / 100 \mathrm{~g}$ de argila seca. Os fluidos de perfuração foram preparadas de acordo com os padrões da Petrobras. Os resultados indicaram que a composição mineralógica das amostras consistiu em montmorilonita, caulinita e quartzo. Quanto às suas propriedades reológicas, as amostras satisfazem parcialmente as exigências da norma Petrobras (Documento: EP-1EP-00011-A padrão 2011/Petrobras).

Observa-se que a partir das caracterizações tecnológicas, pode-se direcionar o real potencial das matérias-primas para aplicações industriais, assunto este também que já foi relatado na bibliografia internacional $[12,13]$.

No Brasil, especificamente no estado do Amapá, as indústrias cerâmicas de telhas e blocos tem uma fundamental importância sócio-econômica, porém ainda é bastante recente a implantação destas indústrias, não conseguindo atender o mercado local. Por isso, tem-se incentivado a busca de novos depósitos com o intuito de suprir as novas indústrias de cerâmica vermelha e branca que estão sendo implantadas no estado e, portanto, abastecer a população local. Para isso, o conhecimento adequado das características físicas, químicas e mineralógica das novas matérias-primas para essas indústrias cerâmicas do Amapá é conveniente, pois pode-se controlar a qualidade, bem como direcionar o real potencial tecnológico dessas argilas $[14,15]$.

Portanto, o objetivo desse trabalho é a caracterização tecnológica de duas novas argilas cujas jazidas estão localizadas na região sul do estado do Amapá. Para isso, as análises se darão por meio das técnicas de análises química, térmica, mineralógica e granulométrica, estudando a possibilidade de seu uso como matérias-primas cerâmicas. Além disso, será analisada a influência do tratamento térmico nessas duas argilas.

\section{MATERIAIS E MÉTODOS}

As argilas denominadas A e B foram secas em uma estufa a $60^{\circ} \mathrm{C}$ durante $24 \mathrm{~h}$. Posteriormente, foram submetidas à moagem em moinhos de martelo e galga com objetivo de transformá-las em pó. Após moagem as argilas foram passadas em peneira ABNT 200 mesh $(0,074 \mathrm{~mm})$ para posteriores ensaios de caracterização.

A caracterização das amostras das argilas foi efetuada por meio das seguintes técnicas: análise granulométrica por espalhamento laser (Cilas 1064 L/D), análise química por fluorescência de raios X (Shimadzu EDX 720), análise termogravimétrica (TG) e análise térmica diferencial (ATD) (sistema de análise térmica 
simultânea Shimadzu TA $60 \mathrm{H}$ ), com taxa de aquecimento $12,5^{\circ} \mathrm{C} / \mathrm{min}$ sob atmosfera de ar (temperatura máxima $1000^{\circ} \mathrm{C}$ e padrão na $\mathrm{ATD}$ o óxido de alumínio calcinado), difração de raios-X (Shimadzu D6000) com radiação Cuk $\alpha(40 \mathrm{kV} / 30 \mathrm{~mA})$ e velocidade do goniômetro de $2^{\circ} \mathrm{C} / \mathrm{min}$ e passo $0,02^{\circ}$, na faixa de 5 a $60^{\circ}$.

Para a análise granulométrica, foi separada $200 \mathrm{~g}$ de argila, água e defloculante e, posteriormente, usada uma peneira ABNT 200 mesh. A utilização do defloculante é importante para evitar a aglomeração e manter as partículas em suspensão. Inicialmente foi feita uma suspensão de argila, água e defloculante, e em seguida foi feita a agitação mecânica.

Para conformação das massas, foi adicionado um teor de umidade de 7,0\% do peso total da argila, e a massa foi homogeneizada no moinho de bolas por $24 \mathrm{~h}$. Depois da homogeneização, as massas foram conformadas por prensagem uniaxial (Servitech CT-335), sendo aplicado uma pré-prensagem sob uma pressão de 13,4MPa e, posteriormente, uma prensagem de 20,0MPa e então a peça foi retirada. Foram confeccionados 30 corpos de prova para cada composição.

Após a etapa de conformação, os corpos de prova foram sinterizados em forno (Flyever FE 50 RP) a $850^{\circ} \mathrm{C}, 1000^{\circ} \mathrm{C}$ e $1200^{\circ} \mathrm{C}$ a uma taxa de aquecimento $5^{\circ} \mathrm{C} / \mathrm{min}$, com permanência de $1 \mathrm{~h}$. Após o processo de sinterização, os corpos de prova foram submetidos a ensaios tecnológicos para determinação das propriedades físico-mecânicas de retração linear de queima (RLq), absorção de água (AA), porosidade aparente (PA), microscopia eletrônica de varredura (MEV) e módulo de ruptura à flexão (MRF). As análises por microscopia eletrônica de varredura somente foram realizadas nas amostras sinterizadas em $1200^{\circ} \mathrm{C}$, sendo avaliadas as superfícies de fraturas dos corpos de prova submetidos ao ensaio sob flexão. A análise morfológica foi conduzida em um microscópio eletrônico de varredura, Shimadzu SSX-550 Superscan, a uma voltagem de 15 $\mathrm{kV}$, sob alto vácuo e as superfícies de fratura dos corpos de prova recobertas com ouro. Após os ensaios, os corpos de prova de cada composição foram submetidos ao processo de moagem e peneiramento em peneira ABNT 200 mesh $(0,074 \mathrm{~mm})$, para posterior caracterização por difração de raios X (DRX).

\section{RESULTADOS E DISCUSSÃO}

Os resultados da análise química são apresentados na Tabela 1. Pode-se observar que o percentual de dióxido de silício $\left(\mathrm{SiO}_{2}\right)$ foi de $61,25 \%$ para a argila A e $51,02 \%$ para a argila B. Com relação ao teor de alumina $\left(\mathrm{Al}_{2} \mathrm{O}_{3}\right)$, os valores foram de $22,49 \%$ para a argila A e $34,60 \%$ para a argila B. Para o óxido de ferro $\left(\mathrm{Fe}_{2} \mathrm{O}_{3}\right)$ nota-se que a argila A apresentou o maior teor, $5,17 \%$, e a argila $\mathrm{B}$ o menor, $3,09 \%$. Os teores de $\mathrm{SiO}_{2}$ estão associados à presença de argilominerais e quartzo, enquanto os de $\mathrm{Al}_{2} \mathrm{O}_{3}$ estão relacionados à caulinita [16]. Observa-se que as duas argilas $\mathrm{A}$ e $\mathrm{B}$ são classificadas como sílico-aluminosos (teor de $\mathrm{Al}_{2} \mathrm{O}_{3}$ menor que $46 \%$ ), sendo que a argila $\mathrm{B}$ possui maior refratariedade em relação à argila $\mathrm{A}$, uma vez que apresenta composição de alumina superior, bem como menores teores de óxidos fundentes [17,18]. Na Tabela 1 ainda pode ser observado que as frações de $\mathrm{Fe}_{2} \mathrm{O}_{3}, \mathrm{MgO}, \mathrm{CaO}$ e $\mathrm{K}_{2} \mathrm{O}$ da argila $\mathrm{A}$ são superiores às da argila $\mathrm{B}$, podendo estar presentes em materiais que irão agir como fundentes durante a etapa de queima. Nota-se que ambas as argilas não apresentaram óxido de sódio $\left(\mathrm{Na}_{2} \mathrm{O}\right)$. Observa-se que a argila $\mathrm{A}$ apresenta composição típica para cerâmica vermelha, com predominância de $\mathrm{SiO}_{2} \mathrm{e} \mathrm{Al}_{2} \mathrm{O}_{3}$, bem como teor de óxido de ferro $\left(\mathrm{Fe}_{2} \mathrm{O}_{3}\right)$ superior a $5 \%$, o que indica que a argila A poderá apresentar, após a queima, coloração vermelha, principalmente devido a oxidação do composto de ferro que ao final apresenta-se sob a forma de óxido férrico $[19,20]$. Por outro lado, a argila B possui composição química típica para argila aplicada em materiais refratários. Conforme CALLISTER [39] os ingredientes principais de uma argila refratária é uma mistura majoritária de $\mathrm{SiO}_{2} \mathrm{e}$ $\mathrm{Al}_{2} \mathrm{O}_{3}$, contendo geralmente entre 25 a $45 \% \mathrm{de}_{\mathrm{Al}_{2} \mathrm{O}_{3}}$. Em relação à perda ao fogo, verifica-se que a argila $\mathrm{A}$ apresentou perda de $6,3 \%$, enquanto a argila $\mathrm{B}$ de $8,9 \%$, estas perdas provavelmente está relacionada à evaporação da água, desidroxilação das massas e queima da matéria orgânica.

Tabela 1: Composições químicas das matérias-primas (\% em peso).

\begin{tabular}{lccccccccc}
\hline Amostras & $\mathbf{P F}^{*}$ & $\mathbf{S i O}_{\mathbf{2}}$ & $\mathbf{A l}_{\mathbf{2}} \mathbf{O}_{\mathbf{3}}$ & $\mathbf{F e}_{\mathbf{2}} \mathbf{O}_{\mathbf{3}}$ & $\mathbf{M g O}$ & $\mathbf{T i O}_{\mathbf{2}}$ & $\mathbf{K}_{\mathbf{2}} \mathbf{O}$ & $\mathbf{C a O}$ & $\mathbf{N a}_{\mathbf{2}} \mathbf{O}$ \\
\hline Argila A & 6,30 & 61,25 & 22,49 & 5,17 & 1,25 & 1,06 & 2,39 & 0,363 & - \\
Argila B & 8,90 & 51,02 & 34,60 & 3,09 & 1,10 & 1,14 & 0,89 & 0,256 & - \\
\hline \multicolumn{2}{c}{ * PF $=$ Perda ao Fogo. } & & & & & &
\end{tabular}

A Figura $1(\mathrm{a}, \mathrm{b})$ apresenta o padrão de difração de raios-X das argilas $\mathrm{A}$ e $\mathrm{B}$ respectivamente. As fases cristalinas presentes na argila A são caulinita, quartzo, mica e esmectita, enquanto a argila B são caulinita, mica e quartzo. A mica é provavelmente a fonte da razoável quantidade de potássio observada na composição química da argila $\mathrm{A}$, o que indica uma possível ação fundente do $\mathrm{K}_{2} \mathrm{O}$ em baixas temperaturas, favorecendo a densificação, com a formação de fase líquida [21]. Com base no padrão de difração da argila A e nas 
composições químicas (Tabela 1), observa-se que a amostra apresentou caulinita mal cristalizada, pois as intensidades dos picos de difração são fracas, porém sua presença é reforçada a partir do teor de óxido de alumínio presente na composição química, bem como, ao fato da inexistência de outras fontes de óxido de alumínio como gibsita ou boemita [22].


Figura 1: Difratogramas de raios $\mathrm{X}$ das amostras: (a) argila A; (b) argila B.

A Tabela 2 e Figura 2 evidência a distribuição granulométrica das duas amostras de argilas A e B. Geralmente, considerar-se a fração argila de uma matéria-prima cerâmica natural, aquela fração com granulométrica de dimensão inferior a $2 \mu \mathrm{m}$, a fração silte, entre 2 e $20 \mu \mathrm{m}$ e a fração areia com diâmetros superiores a $20 \mu \mathrm{m}$. A fração argila está relacionada, sobretudo, aos minerais argilosos, que são os responsáveis pelo desenvolvimento da plasticidade do sistema argila e água [23]. A amostra A é composta de 16,56\% de argila e 52,73\% de silte, com diâmetro médio de $14,47 \mu \mathrm{m}$, já a amostra B apresenta fração volumétrica de 29,50 \% de argila e $67,48 \%$ de silte, diâmetro médio de $6,01 \mu \mathrm{m}$. Constata-se também que a amostra A é a que apresenta um maior diâmetro médio, e a amostra B, o menor, ou seja, a menos argilosa e a mais argilosa, respectivamente. Os resultados obtidos pela análise granulométrica indica que a argila B é mais fina (diâmetro médio das partículas menores), o que contribui para uma maior sinterabilidade durante o processo de queima, devido à maior reatividade das partículas, uma vez que apresenta maior área superficial [24]

Tabela 2: Composição granulométrica das argilas A e B.

\begin{tabular}{|c|c|c|c|c|}
\hline Amostras & $\begin{array}{c}\text { Argila }(\%) \\
(x \leq 2 \mu \mathrm{m})\end{array}$ & $\begin{array}{c}\text { Silte }(\%) \\
(2 \mu \mathrm{m}<\mathrm{x} \leq 20 \mu \mathrm{m})\end{array}$ & $\begin{array}{c}\text { Areia }(\%) \\
(x>20 \mu \mathrm{m})\end{array}$ & $\begin{array}{c}\text { Diâmetro Médio } \\
(\mu \mathrm{m})\end{array}$ \\
\hline Argila A & 16,56 & 52,73 & 30,71 & 14,47 \\
\hline Argila B & 29,50 & 67,48 & 3,02 & 6,01 \\
\hline
\end{tabular}

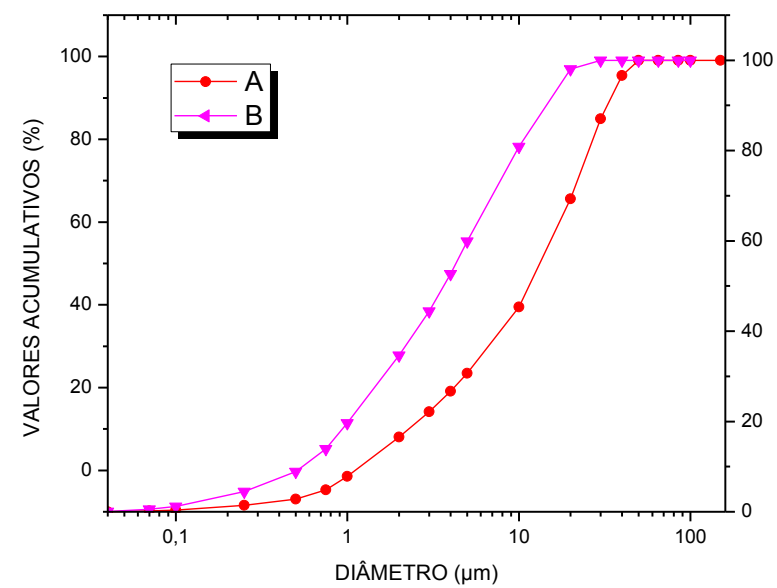

Figura 2: Distribuição granulométrica das argilas A e B. 
A Tabela 3 apresenta os valores de limite de plasticidade (LP), liquidez (LL) e índice de plasticidade (IP) das argilas A e B. Segundo CAPUTO [40], pode-se classificar a plasticidade das argilas conforme o IP em: (1) fracamente plástica ( $1<\mathrm{IP}<7)$; (2) mediamente plástica $(7<\mathrm{IP}<15)$ e (3) altamente plástica (IP $>15)$.

Observa-se que os limites de liquidez (LL) foi de 36,1 (Argila A) e 43,0 \% (Argila B) respectivamente. $\mathrm{O}$ índice de plasticidade para a argila B foi 33,5\%, enquanto para a argila A ficou em 10,5\%. A argila B é altamente plástica (IP > 15\%), característica atribuída provavelmente aos maiores teores da fração argila, bem como ao menor diâmetro médio das partículas. Constata-se ainda que a argila B apresentou valor superior a 30\% no índice de plasticidade, o que indica que pode ser necessário a adição de material não-plástico para o seu processamento. Já a argila A apresentou uma plasticidade média $(7<$ IP $<15)$, o que pode ser atribuída ao elevado teor de sílica (Tabela 1), no qual reduz a plasticidade. Portanto, observa-se que os limites de Atterber (LP; LL e IP) obtidos para as argilas A e B corroboram com os resultados de composição química e granulométrica. Conforme SANTOS et al. [25], a partir do índice de plasticidade e do limite de plasticidade pode-se classificar as argilas em zona de extrusão ótima e zona de extrusão aceitável. Para uma extrusão aceitável a argila deve apresentar índice de plasticidade entre 10 e $34 \%$ e limite de plasticidade entre 18 e $31 \%$.

No entanto, para uma extrusão ótima a argila deve apresentar índice de plasticidade entre 15 e $25 \%$ enquanto o limite de plasticidade deve estar entre 18 e 25\%. Observa-se na Tabela 3, que nenhuma das duas argilas apresenta IP e LP compatível com a zona ótima de extrusão, enquanto a argila A possui IP e LP dentro da zona de extrusão aceitável.

Tabela 3: Limites de Atterberg das amostras.

\begin{tabular}{cccc}
\hline Amostras & LL (\%) & LP (\%) & IP (\%) \\
\hline Argila A & 36,1 & 25,7 & 10,5 \\
Argila B & 43,0 & 9,5 & 33,5 \\
\hline
\end{tabular}

A Figura 3, a seguir, apresenta as curvas simultâneas de análise térmica diferencial (ATD) e análise gravimétrica (ATG) das argilas A e B.
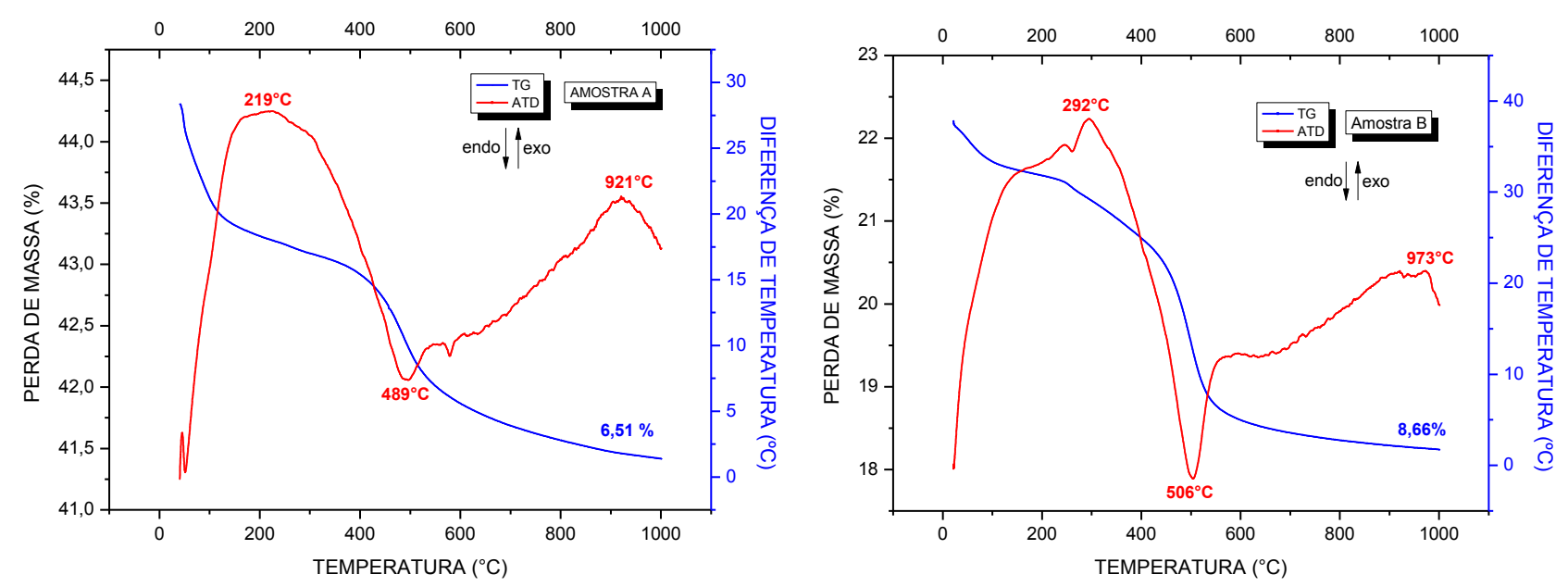

Figura 3: Curvas de ATG/ATD das amostras: (a) argila A; (b) argila B.

Observa-se na Figura 3 (a,b), que as curvas ATG apresentaram perda de massa total de 6,5\% para a argila A e 8,66 \% para a argila $\mathrm{B}$. Observa-se que a perda de massa até $140^{\circ} \mathrm{C}$ pode ser atribuída à evaporação das águas livre e adsorvida. Entre 140 e $600^{\circ} \mathrm{C}$, a perda de massa é correspondente à oxidação da matéria orgânica e à desidroxilação das massas, e, em seguida, acima de $600^{\circ} \mathrm{C}$, a perda de massas é essencialmente devida à oxidação da matéria orgânica. As perdas de massas são confirmadas pela análise química, que apresenta perdas ao fogo aproximadas aos valores encontrados nas análises termogravimétricas. Já nas curvas de análise térmica diferencial (ATD) verifica-se que entre as temperaturas de $200^{\circ} \mathrm{C}$ a $300^{\circ} \mathrm{C}$, ocorrem bandas exotérmicas, provavelmente, devido às reações da matéria orgânica. Foram observados dois picos endotérmicos, um para a argila $\mathrm{A}\left(489^{\circ} \mathrm{C}\right)$ e outro para a argila $\mathrm{B}\left(506^{\circ} \mathrm{C}\right)$, os quais correspondem possivelmente à presença de hidróxido. Nas temperaturas de $921^{\circ} \mathrm{C}$ (argila A) e $973^{\circ} \mathrm{C}$ (argila B) observou-se um pico exotérmico, e que decorre, provavelmente, devido à nucleação da mulita [26-28]. 
As Figuras $4 \mathrm{a}$ e b apresentam as cores dos corpos de prova das argilas após queima a $850^{\circ} \mathrm{C}, 1000^{\circ} \mathrm{C}$ e $1200^{\circ} \mathrm{C}$. Observa-se que a amostra A apresentou característica de argila para cerâmica vermelha, apresentando cor marrom avermelhada após queima a $850^{\circ} \mathrm{C}$, laranja em $1000^{\circ} \mathrm{C}$ e vermelha a $1200^{\circ} \mathrm{C}$. Nos estudos de TEXEIRA et al. [29] foi reportado que acima de $1000^{\circ} \mathrm{C}$ ocorre a liberação de ferro bivalente, que por oxidação passa a ferro trivalente responsável pela cor vermelha e em temperaturas acima de $1100^{\circ} \mathrm{C}$, começa a ocorrer uma superqueima e o ferro trivalente começa a reduzir gerando a cor marrom avermelhado escuro a preto. Por outro lado, a amostra B queima com cor creme nas temperaturas a 850 e $1000^{\circ} \mathrm{C}$ e com cor amarelo claro a $1200^{\circ} \mathrm{C}$. Baseado nas cores das argilas A e B, o provável uso é para cerâmica vermelha ou estrutural (argila A) e em cerâmica branca, bem como fabricação de material refratário sílico-aluminoso respectivamente. A argila $\mathrm{B}$ apresenta um teor de alumina $\left(\mathrm{Al}_{2} \mathrm{O}_{3}\right)$ de $34,90 \%$ (Tabela 1), porosidade aparente menor que $45 \%$ (Figura 7), bem como queima na cor clara, o que segundo a norma ABNT - NBR 10237 [40] classifica como um material refratário sílico-aluminoso denso.
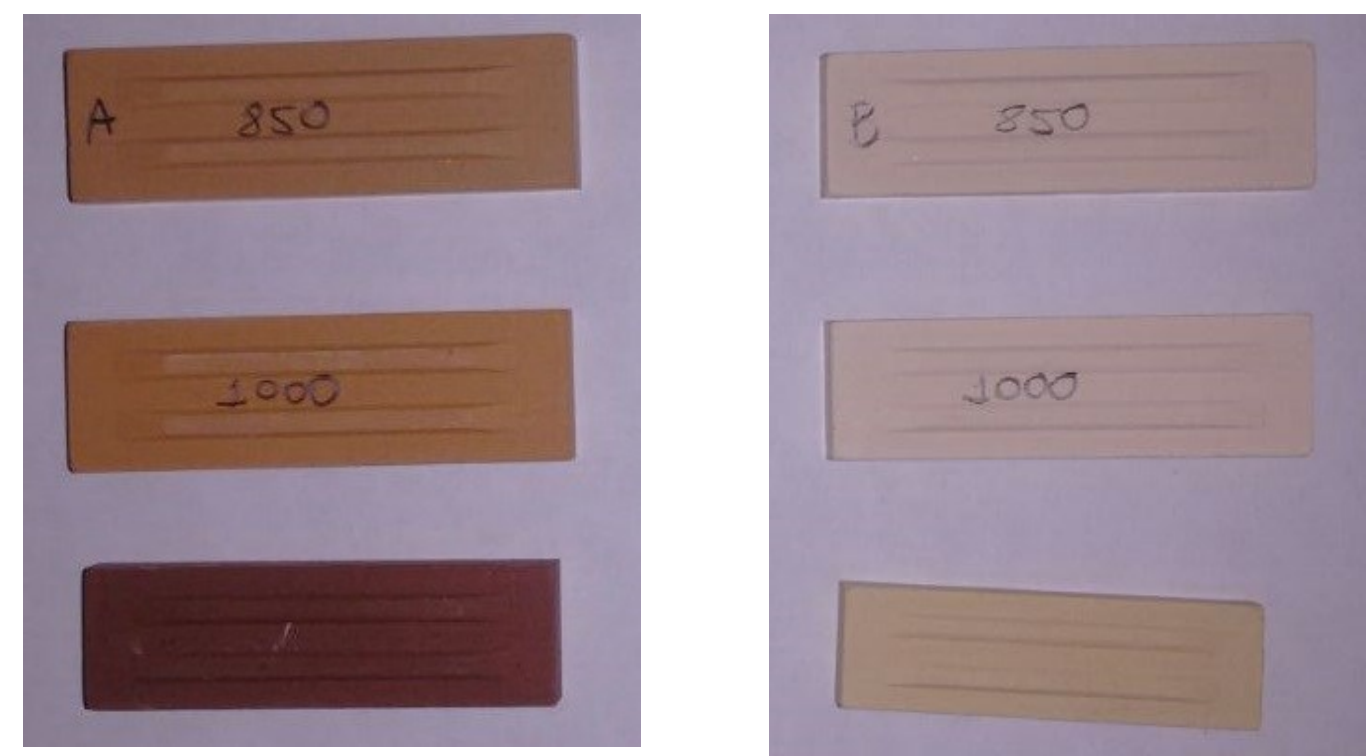

Figura 4: Cores dos corpos de prova após queima a 850,1000 e $1200^{\circ} \mathrm{C}$ : (a) argila A; (b) argila B.

As Figuras 5 a 8 mostram os resultados dos ensaios físico-mecânicos das argilas A e B após queima a 850,1000 e $1200^{\circ} \mathrm{C}$. A Figura 5 apresenta os valores obtidos para retração linear após a queima das argilas A e B a 850,1000 e $1200^{\circ} \mathrm{C}$. Observa-se que a retração linear aumenta com o aumento da temperatura de sinterização para as argilas A e B. Assim sendo, este comportamento estaria provavelmente relacionado ao maior grau de sinterização e densificação das argilas, induzidas por mudanças físicas e redução do volume dos corpos de prova [30].

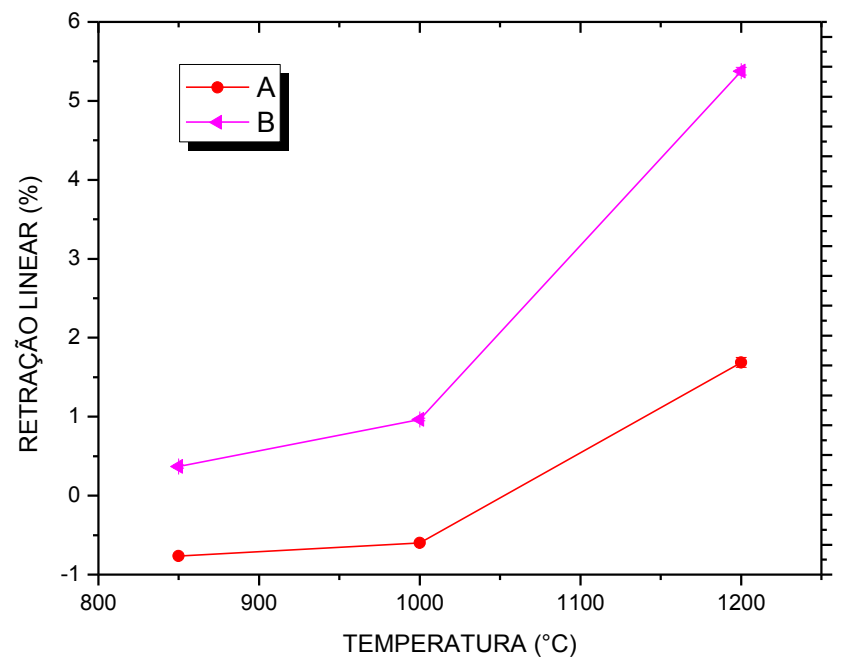

Figura 5: Retração linear de queima dos corpos de prova das argilas A e B. 
A Figura 6 apresenta os valores obtidos para absorção de água após a queima das argilas a 850, 1000 e $1200^{\circ} \mathrm{C}$. Observa-se que o teor de absorção de água das duas argilas tende a diminuir com o aumento da temperatura, sendo esta queda mais pronunciada na temperatura de $1200^{\circ} \mathrm{C}$. Tal fato é atribuído ao preenchimento dos poros devido à fusão dos óxidos fundentes presente nas massas cerâmicas, o que promove uma redução da porosidade e, consequentemente, maior empacotamento da peça. A argila A por conter maior quantidade de óxidos fundentes promoveu a menor absorção de água. $\mathrm{O}$ comportamento da argila $\mathrm{B}$ pode ser atribuído ao menor teor de óxidos alcalinos e alcalinos terrosos, bem como a elevada quantidade de $\mathrm{Al}_{2} \mathrm{O}_{3}$ que dificulta a formação de fase líquida $[31,32]$. Além disso, a maior perda ao fogo da argila $\mathrm{B}$ contribui para um aumento na absorção de água, pois aumenta a porosidade da peça.

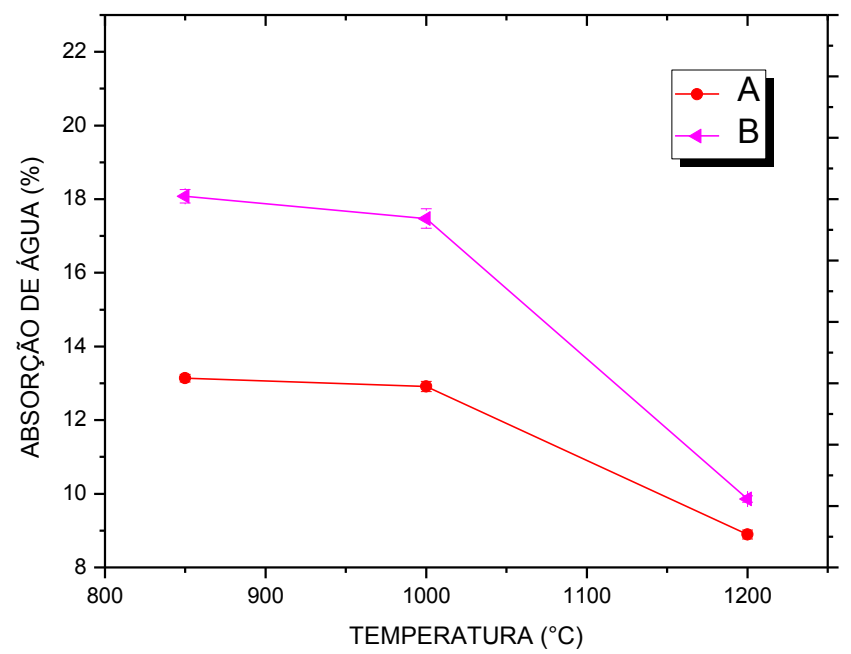

Figura 6: Absorção de água dos corpos de prova após queima das argilas A e B.

A Figura 7 apresenta os valores de porosidade aparente para 850,1000 e $1200^{\circ} \mathrm{C}$. Observa-se uma diminuição da porosidade aparente das duas argilas com o aumento da temperatura de queima, provavelmente em virtude da formação de fase liquida, retraindo a peça e reduzindo desta forma a porosidade [33].

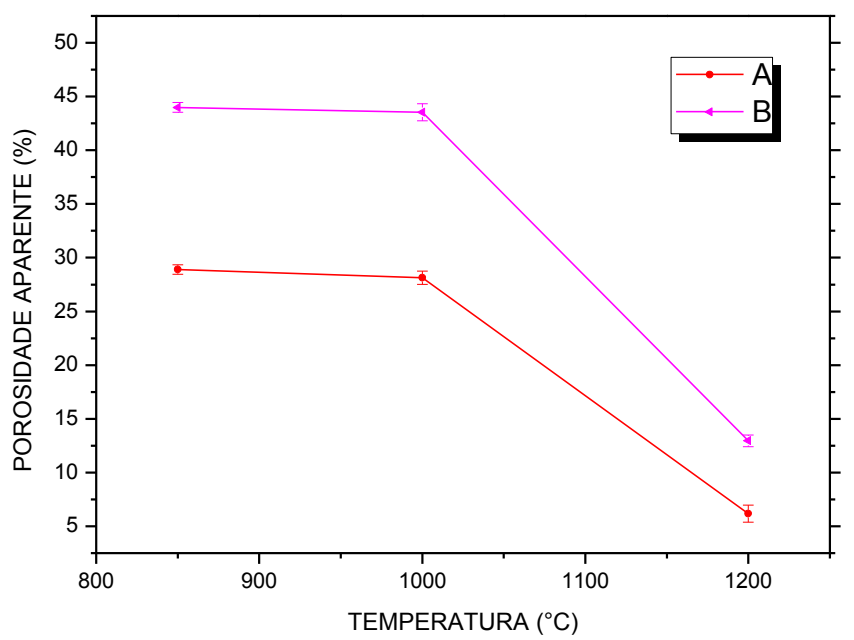

Figura 7: Porosidade aparente dos corpos de prova após queima das argilas A e B.

A Figura 8 apresenta os valores obtidos para módulo de ruptura sob flexão após a queima dos corpos de prova obtidos com as argilas A e B para 850, 1000 e $1200^{\circ} \mathrm{C}$. Observa-se na Figura 8, que o módulo de ruptura cresce com o aumento da temperatura de queima para as duas argilas. Isto indica que a razão principal é provavelmente a redução da porosidade nas peças, o que é desejável, pois o efeito deletério da porosidade sobre a resistência mecânica está fundamentalmente relacionado aos seguintes fatores: i) os poros reduzem a área da seção cruzada na qual a carga é aplicada; e ii) os poros atuam como concentradores de tensão [34]. Constata-se também, que na faixa de 850 até $1000^{\circ} \mathrm{C}$, não ocorre variação significativa do módulo de 
ruptura entre as argilas $\mathrm{A}$ e $\mathrm{B}$, porém na temperatura de queima de $1200^{\circ} \mathrm{C}$, torna-se mais perceptível a diferença, sendo o melhor desempenho mecânico para a argila A. Analisando esse melhor desempenho da argila A, pode-se correlacionar com a composição química (Tabela 1). Observou que a argila A apresentou maior teor de óxidos fundentes, o que segundo GOES [35] atuam na formação da fase líquida preenchendo os vazios na microestrutura, contribuindo para aumentar a densificação e reduzir a porosidade, o que é corroborado com a morfologia da Figura 10a.

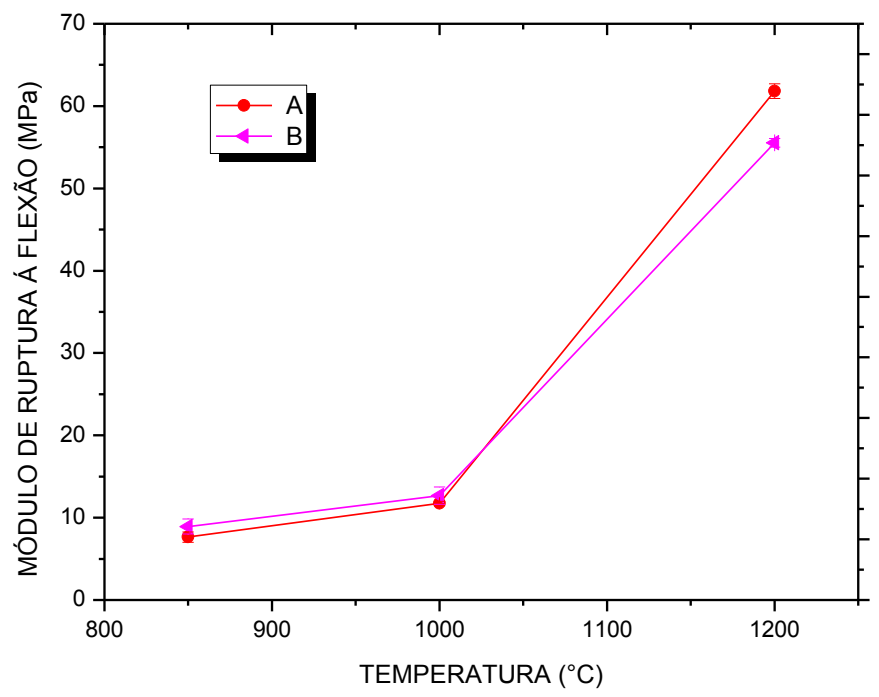

Figura 8: Módulo de ruptura à flexão dos corpos de prova após queima das argilas A e B.

Com os dados das Figuras 6 e 8, pode-se analisar as prováveis aplicações da argila C. A Tabela 4 evidencia os limites das propriedades conforme reportado na literatura e normas.

Tabela 4: Limites indicados para absorção de água e módulo de ruptura para tijolos de alvenaria, furados e telhas conforme [41-45].

\begin{tabular}{cccc}
\hline Argila C & Tijolos de Alvenaria & Tijolos Furados & Telhas \\
\hline $\begin{array}{c}\text { Absorção de Água } \\
\text { Máxima (\%) }\end{array}$ & $8-25$ & 25 & 20 \\
$\begin{array}{c}\text { Módulo de Ruptura } \\
\text { Mínimo (MPa) }\end{array}$ & 2 & 5,5 & 6,5 \\
\hline
\end{tabular}

Comparando-se os resultados da Tabela 4 e os resultados das Figuras 6 e 8, chega-se às seguintes conclusões quanto às aplicações da argila $\mathrm{C}$ em cerâmica vermelha.

\begin{tabular}{cccc}
\hline Temperatura de Queima $\left({ }^{\mathbf{}} \mathbf{C}\right)$ & Tijolos de Alvenaria & Tijolos Furados & Telhas \\
\hline 850 & Possível & Possível & Inadequado \\
1000 & Possível & Possível & Possível \\
1200 & Possível & Possível & Possível \\
\hline
\end{tabular}

* Módulo de ruptura abaixo do especificado.

A Figura 9 apresenta difratogramas de raios-X das argilas $\mathrm{A}$ e $\mathrm{B}$ após queima nas temperaturas de 850,1000 e $1200^{\circ} \mathrm{C}$. 

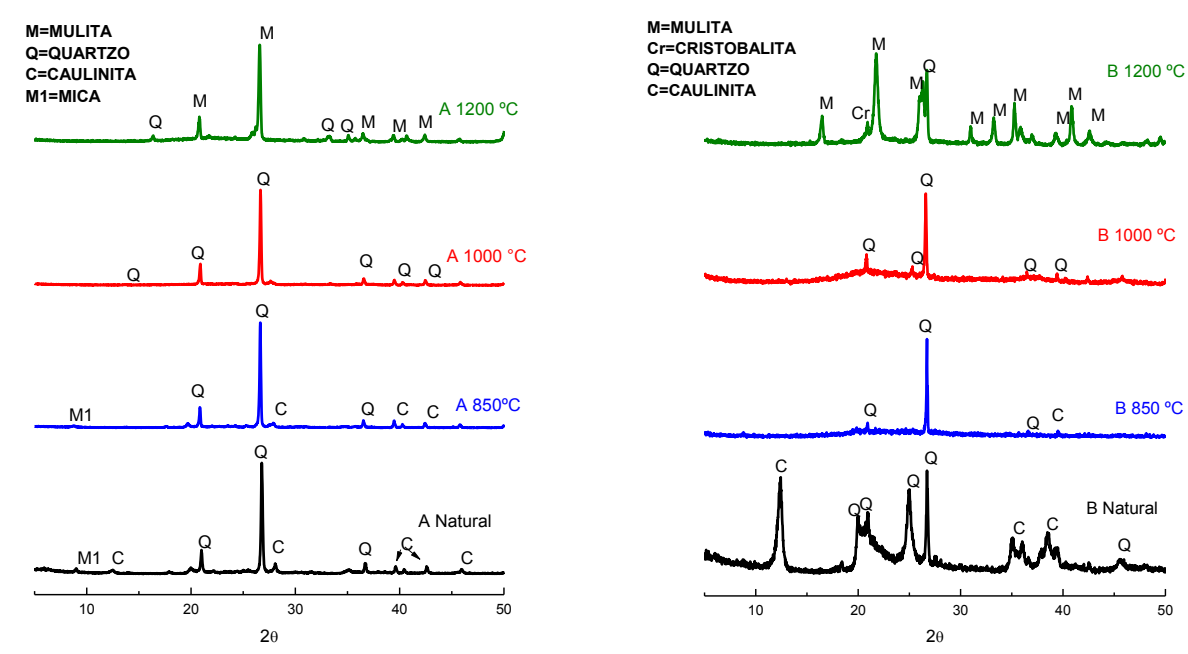

Figura 9: Difratogramas de raios-X das amostras após queima nas temperaturas de 850,1000 e $1200{ }^{\circ} \mathrm{C}$.

Observa-se na Figura 9, a evolução das fases cristalinas presentes nas argilas, A e B, em função da temperatura de queima, podendo ser verificada a $850^{\circ} \mathrm{C}$ que as fases cristalinas nas amostras são mica, quartzo e caulinita na argila $\mathrm{A}$, sendo quartzo e caulinita na argila $\mathrm{B}$; a $1000^{\circ} \mathrm{C}$ observa-se apenas a presença de quartzo nas argilas A e B; a $1200^{\circ} \mathrm{C}$ quartzo e a mulita são detectados na argila $\mathrm{A}$, enquanto quartzo, mulita e cristobalita na argila B. A nucleação e crescimento dos cristais de mulita só foram observados a partir da temperatura de $1100^{\circ} \mathrm{C}$ nos estudos de CONCONI et al. [36] e GONÇALVES et al. [37]. Ainda pode-se constatar que a destruição da estrutura cristalina da caulinita ocorre em temperaturas abaixo da temperatura de $1000^{\circ} \mathrm{C}$ para as duas argilas, bem como a nucleação da mulita se intensificam depois de atingida a temperatura de $1200^{\circ} \mathrm{C}$. Conforme VIEIRA e MONTEIRO [38], a mulita é uma fase desejável que confere elevada resistência mecânica ao material cerâmico. A diminuição da intensidade dos picos de difração do quartzo indica que ocorreu sua dissolução na fase líquida formada. Portanto, observa-se que as amostras A e B queimadas a $1200^{\circ} \mathrm{C}$, já constata-se uma significativa presença de mulita e diminuição na intensidade dos picos de difração do quartzo, sendo mais pronunciada para a amostra A. Sendo assim, provavelmente foi um fator decisivo a intensificação dos picos de mulita para a melhora do módulo de ruptura das duas argilas.

A Figura 10 evidencia as morfologias obtidas no microscópio eletrônico de varredura das argilas A e $\mathrm{B}$, sendo analisadas as amostras sinterizadas a $1200^{\circ} \mathrm{C}$.
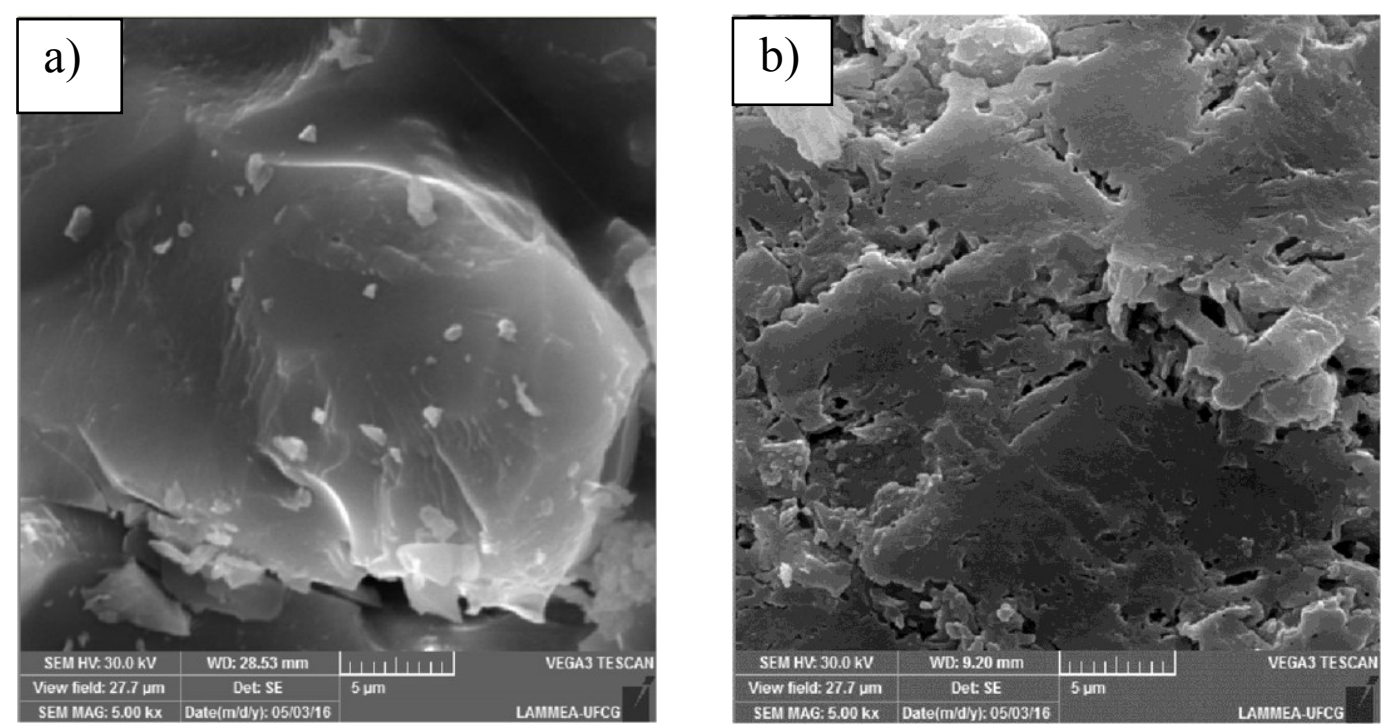

Figura 10: Micrografias obtidas por MEV das amostras sinterizadas a $1200^{\circ} \mathrm{C}$ : (a) argila A; (b) argila B. 
Observa-se na Figura 10a que a argila A apresenta uma microestrutura com textura lisa, praticamente homogênea e altamente densificada, enquanto a micrografia da Figura 10b mostra que a argila B apresenta uma superfície de fratura com textura bastante rugosa, evidenciando fratura do tipo intergranular, bem como a ocorrência de arrancamento de material durante a solicitação mecânica. Ainda observa-se na Figura 10b, que a argila $\mathrm{B}$ apresenta uma maior quantidade de poros em relação à argila $\mathrm{A}$, tal fato, provavelmente foi decisivo para diminuir o módulo de ruptura em relação à argila $\mathrm{A}$.

\section{CONCLUSÕES}

As características de duas argilas do sul do Estado do Amapá foram estudadas. A partir das análises química, térmica, mineralógica, granulométrica e físico-mecânica das duas argilas, pôde-se concluir que as amostras apresentaram na sua composição mineralógica esmectita, caulinita, mica e quartzo para a argila A, enquanto a argila B caulinita, mica e quartzo. Observou-se que o teor de absorção de água das duas argilas tende a diminuir com o aumento da temperatura, enquanto que o módulo de ruptura cresce com o aumento da temperatura de queima para as duas argilas. Devido ao seu menor grau de empacotamento a seco e maior perda de massa durante a queima, a argila B apresenta maiores valores de absorção de água e de retração linear de queima do que a argila A. Assim sendo, com a caracterização das argilas A e B, pôde-se inferir, que a argila A é apropriada para aplicações na indústria de cerâmica vermelha (blocos, tijolos e telhas), já a argila B pode-se usar em aplicações para refratários densos.

\section{AGRADECIMENTOS}

A UFCG/CAPES pelo auxilio financeiro, bem como, aos colegas do laboratório de tecnologia de materiais cerâmicos da Universidade Federal de Campina Grande, pela ajuda nos procedimentos experimentais.

\section{BIBLIOGRAFIA}

[1] FERRARI, K. R., FIGUEIREDO, P. M., MACHADO, L. A., et al., “Transformações das matérias-primas do suporte durante a queima de revestimento cerâmico", Cerâmica Industrial, v. 5, n. 2, pp. 53-58, 2000.

[2] SMITH, W. F., HASHEMI, J. "Introdução à engenharia e ciência dos materiais", In: Affonso, A. J, Fundamentos de Engenharia e Ciência dos Materiais, 5 ed., Capítulo 1, Porto Alegre - BR, AMGH Editora LTDA, 2012.

[3] SMITH, W. F., HASHEMI, J. "Cerâmica”, In: Affonso, A. J, Fundamentos de Engenharia e Ciência dos Materiais, 5 ed., Capítulo 1, Porto Alegre - BR, AMGH Editora LTDA, 2012.

[4] ANICER, ASSOCIAÇÃO NACIONAL DA INDÚSTRIA CERÂMICA, http://portal.anicer.com.br/ setor/. Acessado em Maio de 2015.

[5] PRADO, U. S., BRESSIANI, J. C., "Panorama da indústria cerâmica brasileira na última década", Cerâmica Industrial, v. 18, n. 1, pp. 7-11, 2013.

[6] BUSTAMANTE, G. M., BRESSIANI, J. C., “A Indústria cerâmica brasileira”, Cerâmica Industrial, v. 5, n. 3, pp. 31-36, 2000.

[7] TANNO, L. C., MOTTA, J. F. M., "Panorama setorial - minerais industriais", Cerâmica Industrial, v. 5, n. 3, pp. 37-40, 2000.

[8] SANTOS, P. S., “Argilas”, In: Santos, H. S, Ciência e Tecnologia de Argilas, 2 ed., Capítulo 1, São Paulo - BR, Editora Edgard Blucher LTDA, 1989.

[9] RAMOS, S. O., MACEDO, R. S., CARTAXO, J. M., et al., "Caracterização de argilas usadas para cerâmica estrutural”, Revista Eletrônica de Materiais e Processos, v.5, n.3, pp. 65-70, 2010.

[10] DUTRA, R. P. S., VARELA, M. L., NASCIMENTO, R. M., et al., "Avaliação da potencialidade de argilas do Rio Grande do Norte - Brasil”, Cerâmica Industrial, v. 11, n. 2, pp. 42-46, 2006.

[11] SILVA, I. A., COSTA, J. M. R., MENEZES, R. R., et al., "Studies of new occurrences of bentonite clays in the State of Paraíba for use in water based drilling fluids", Rem: Revista Escola de Minas, v. 66, n. 4, pp. 485-491, 2013.

[12] SEI, J., TOURÉ, A. A., FOURCADE, J. O., et al., "Characterisation of kaolinitic clays from the Ivory Coast (West Africa)", Applied Clay Science, v. 27, n. 3, pp. 235-239, 2004.

[13] DONDI, M. "Clay materials for ceramic tiles from the Sassuolo District (Northern Apennines, Italy). Geology, composition and technological properties”, Applied. Clay Science, v. 15, n. 3, p. 337-366, 1999. 
[14] SOUTO, F. A. F., "Avaliação das características físicas, químicas e mineralógicas da matéria-prima utilizada na indústria de cerâmica vermelha nos municípios de Macapá e Santana-AP”, Dissertação de Ms., CCT/UFPA, Belém, PA, Brasil, 2009.

[15] GARCIA, E., JUNIOR, M. C., QUARCIONI, V. A., et al., "Avaliação da atividade pozolânica dos resíduos de cerâmica vermelha produzidos nos principais polos ceramistas do Estado de S. Paulo", Cerâmica, v.61, n.358, pp. 251-258, 2015.

[16] MACEDO, R. S., MENEZES, R. R., NEVES, G. A., et al., "Influência de aditivos na produção de blocos cerâmicos", Cerâmica, v.54, n.331, pp. 373-381, 2008.

[17] SANTOS, P. S., "Identificação mineralógica de argilas- análise química e capacidade de troca de cátions”, In: Santos, H. S, Ciência e Tecnologia de Argilas, 2 ed., Capítulo 11, São Paulo - BR, Editora Edgard Blucher LTDA, 1989.

[18] SILVA, A. L., CHAVES, A. C., NEVES, G. A., et al, "Reaproveitamento de rejeitos de tijolos na obtenção de membranas cerâmicas destinada a tratamento de efluentes", Revista de Engenharia e Tecnologia, v.7, n.3, pp. 90-104, 2015.

[19] BATISTA, V.R., NASCIMENTO, J.J.S., LIMA, A.G.B., "Secagem e retração volumétrica de tijolos cerâmicos maciços e vazados: uma investigação teórica e experimental", Matéria (Rio J.), v.14, n.4, pp. 1008-1100, 2009.

[20] MACEDO, R. S., "Estudo comparativo entre massas cerâmicas industriais e aditivadas para uso em blocos cerâmicos", Tese de D.Sc., CCT/UFCG, Campina Grande, PB, Brasil, 2005.

[21] MENEZES, R. R., ALMEIDA, R. R., SANTANA, L. N. L., et al., "Utilização do resíduo do beneficiamento do caulim na produção de blocos e telhas cerâmicos", Matéria (Rio J.), v.12, n.1, pp. 226-236, 2007.

[22] MACEDO, R. S., MENEZES, R. R., NEVES, G. A., et al., "Estudo de argilas usadas em cerâmica vermelha", Cerâmica, v.54, n.332, pp. 411-417, 2008.

[23] ARAÚJO, N. C., RAMOS, A. P., QUEIROZ, A. J. P., et al., "Propriedades mecânicas de tijolos fabricados com solo e água residuária de mandioca", Revista Verde de Agroecologia e Desenvolvimento Sustentável, v.10, n. 2, pp. 213-217, 2015.

[24] MURRAY, H. H., "Traditional and new applications for kaolin, smectite, and palygorskite: a general overview", Applied Clay Science, v.17, n. 5, pp. 207-221, 2000.

[25] SANTOS, C. V. P., SILVA, A. R., FILHOS, M. A. S. G., et al., "Índice de Plasticidade e Análise Racional de Argilas de Marabá (PA) para Avaliação das Zonas de Extrusão" Cerâmica Industrial, v. 17, n.2, pp. 25-27, 2012.

[26] AMORIM, L. V., VIANA, J. D., FARIAS, K. V., et al., "Estudo Comparativo entre Variedades de Argilas Bentoníticas de Boa Vista, Paraíba", Matéria (Rio J.), v.11, n.1, pp. 30-40, 2006.

[27] BATISTA, V.R., NASCIMENTO, J.J.S., LIMA, A.G.B., "Secagem e queima de tijolos cerâmicos maciços e vazados incluindo variações dimensionais e danos estruturais", Revista Eletrônica de Materiais e Processos, v.3, n.1, pp. 46-61, 2008.

[28] CAPITANEO, J. L., VIEIRA, C. M. F., MONTEIRO, S. N., et al., "Caracterização tecnológica de argila branca do município de Silva Jardim", In: Congresso Brasileiro de Engenharia e Ciência dos Materiais, pp. 173-179, Natal, Novembro. 2002.

[29] TEXEIRA, A. L., BORGES, D. C. M., SILVA, J. A., et al., "Influência dos tipos de matérias-primas e das condições de queima na cor do suporte cerâmico", Revista Técnico Científico (IFSC), v. 3, n. 1, pp. 135$143,2012$.

[30] BRITO, I. P., ALMEIDA, E. P., NEVES, G. A., et al., "Avaliação de novos depósitos de argilas do Estado da Paraíba visando sua aplicação como matérias-primas cerâmicas", Cerâmica, v.61, n. 360, pp. 391398, 2015.

[31] VIEIRA, C. M. F., SALES, H. F., MONTEIRO, S. N., "Efeito da adição de argila fundente ilítica em cerâmica vermelha de argilas cauliníticas", Cerâmica, v.50, n. 315, pp. 239-246, 2004.

[32] RIBEIRO, A. P., BABISK, M. P., MONTEIRO, S. N., et a., "Desenvolvimento de massa cerâmica com argilas de Campos dos Goytacazes e Itaborá", In: $56^{\circ}$ Congresso Brasileiro de Cerâmica, pp. 759-767, Curitiba, Junho. 2012.

[33] PORTO, V. S., SILVA, M, F., CRUZ, T. B., et al., "Obtenção e avaliação das propriedades físicomecânica de massas cerâmicas para grés sanitários utilizando resíduo de vidro plano em sua composição", Revista Eletrônica de Materiais e Processos, v.7, n.1, pp. 13-19, 2012. 
[34] PINHEIRO, B. C. A., HOLANDA, J. N. F., "Efeito da temperatura de queima em algumas propriedades mecânicas de cerâmica vermelha", Cerâmica, v.56, n.339, pp.237-243, 2010.

[35] GOES, J. R., "Modelos de previsão de propriedades para revestimentos cerâmico usando planejamento fatorial”, Tese de D.Sc., CCT/UFS, São Cristovão, SE, Brasil, 2014.

[36] CONCONI, M. S., GAUNA, M. R., SERRA, M. F., et al., "Quantitative firing transformations of a triaxial ceramic by X-ray diffraction methods", Cerâmica, v.60, n.356, pp.524-531, 2014.

[37] GONÇALVES, W. P., SILVA, V. F., GOMES, J., et al., "Avaliação da influência de diferentes tratamentos térmicos sobre as transformações de fases esmectitas", Cerâmica, v.60, n. 355, pp.316-322, 2014.

[38] VIEIRA, C. M. F., MONTEIRO, S. N., "Influência da temperatura de queima na microestrutura de argilas de Campos dos Goytacazes-RJ", Cerâmica, v.49, n. 309, pp.6-10, 2003.

[39] CALLISTER, W. D. J. “Aplicações e processamento das cerâmicas”, In: Soares, S. M. S.; Miranda, P. E. V., Ciência e engenharia de materiais uma introdução, 5 ed., Capítulo 14, Rio de Janeiro - BR, LTC Editora LTDA, 2002.

[40] CAPUTO, H. P., Mecânica dos solos e suas aplicações fundamentais, 6 ed., Rio de Janeiro, LTC, 1996.

[41] Associação Brasileira de Normas Técnicas. NBR 10237: Materiais refratários - classificação. Rio de Janeiro, 2001.

[42] SANTOS, P. S., Ciência e tecnologia das argilas, 2 ed., São Paulo - BR, Editora Edgard Blucher LTDA, 1989.

[43] Associação Brasileira de Normas Técnicas. NBR 15310: Componentes cerâmicos- Telhas - terminologia, requisitos e métodos de ensaio. Rio de Janeiro, 2005.

[44] Associação Brasileira de Normas Técnicas. NBR 7170: Tijolos maciços cerâmico para alvenaria. Rio de Janeiro, 1983.

[45] Universidade Federal de Ouro Preto, http://www.em.ufop.br/deciv/departamento/ Guilherme / CERAMICOS.pdf. Acessado em Junho de 2016. 